DePauw University

Scholarly and Creative Work from DePauw University

2014

\title{
Cardiac Repair and Regenerative Potential in the Goldfish (Carassius auratus) Heart
}

Jamie Grivas

DePauw University, jamiegrivas@depauw.edu

Maria Haag

DePauw University, mariahaag_2013@depauw.edu

Adedoyin Johnson

DePauw University, adedoyinjohnson_2013@depauw.edu

Trina Manalo

DePauw University, trinamanalo_2014@depauw.edu

Julia Roell

DePauw University, juliaroell_2016@depauw.edu

See next page for additional authors

Follow this and additional works at: https://scholarship.depauw.edu/bio_facpubs

Part of the Biology Commons

\section{Recommended Citation}

Grivas, Jamie, Maria Haag, Adedoyin Johnson, Trina Manalo, Julia Roell, Tanmoy L. Das, Evelyn Brown, Alan R. Burns, Pascal J. Lafontant. "Cardiac repair and regenerative potential in the goldfish (Carassius auratus) heart," Compartive Biochemistry and Physiology C . http://dx.doi.org/10.1016/ j.cbpc.2014.02.002

This Article is brought to you for free and open access by the Biology at Scholarly and Creative Work from DePauw University. It has been accepted for inclusion in Biology Faculty publications by an authorized administrator of Scholarly and Creative Work from DePauw University. 


\section{Authors}

Jamie Grivas, Maria Haag, Adedoyin Johnson, Trina Manalo, Julia Roell, Lala Tanmoy Das, and Pascal J. Lafontant 


\title{
Cardiac repair and regenerative potential in the goldfish (Carassius auratus) heart ${ }^{\text {th }}$
}

\author{
Jamie Grivas a,1, Maria Haag ${ }^{\mathrm{a}, 1}$, Adedoyin Johnson ${ }^{\mathrm{a}, 1}$, Trina Manalo ${ }^{\mathrm{a}, 1}$, Julia Roell ${ }^{\mathrm{a}}$, Tanmoy L. Das ${ }^{\mathrm{a}}$, \\ Evelyn Brown ${ }^{\mathrm{b}}$, Alan R. Burns ${ }^{\mathrm{b}}$, Pascal J. Lafontant ${ }^{\mathrm{a}, *}$ \\ a DePauw University, Department of Biology, Greencastle, IN, USA \\ b College of Optometry, University of Houston, Houston, TX, USA
}

\section{A R T I C L E I N F O}

\section{Article history:}

Received 14 November 2013

Received in revised form 29 January 2014

Accepted 10 February 2014

Available online $\mathrm{xxxx}$

\section{Keywords:}

Cardiac repair

Danio

Fibroblasts

Goldfish

Heart

Inflammation

Regeneration

Remodeling

\begin{abstract}
A B S T R A C T
The remarkable ability of the heart to regenerate has been demonstrated in the zebrafish and giant danio, two fish members of the cyprinid family. Here we use light and electron microscopy to examine the repair response in the heart of another cyprinid, the goldfish (Carassius auratus), following cautery injury to a small portion of its ventricular myocardium. We observed a robust inflammatory response in the first two weeks consisting primarily of infiltrating macrophages, heterophils, and melanomacrophages. These inflammatory cells were identified in the lumen of the spongy heart, within the site of the wound, and attached to endocardial cells adjacent to the site of injury. Marked accumulation of collagen fibers and increased connective tissue were also observed during the first and second weeks in a transition zone between healthy and injured myocardium as well as in adjacent sub-epicardial regions. The accumulation of collagen and connective tissue however did not persist. The presence of capillaries was also noted in the injured area during repair. The replacement of the cauterized region of the ventricle by myocardial tissue was achieved in 6 weeks. The presence of ethynyl deoxyuridinepositive cardiac myocytes and partially differentiated cardiac myocytes during repair suggest effective cardiac myocyte driven regeneration mechanisms also operate in the injured goldfish heart, and are similar to those observed in zebrafish and giant danio. Our data suggest the ability for cardiac regeneration may be widely conserved among cyprinids.
\end{abstract}

(c) 2014 Elsevier Inc. All rights reserved.

\section{Introduction}

Cardiovascular disease is the primary cause of death in the Western world. Replacement of cardiac tissue loss following myocardial infarction in humans is an area of intense research. Recently, regeneration of the ventricular myocardium was documented following resection and ischemic myocardial infarction in neonatal mouse heart (Porrello et al., 2011; Porrello et al., 2013). While a number of studies report regeneration in the adult mammalian ventricular myocardium (Leferovich et al., 2001; van Amerongen et al., 2008; Ellison et al., 2013), the general consensus is that regeneration of the adult mammalian heart is severely limited (Laflamme and Murry, 2011). Various levels of cardiac myogenesis and cardiac myocyte turnover have been reported in the adult human

\footnotetext{
is This paper is based on a presentation given at the 6th Aquatic Annual Models of Human Disease Conference, hosted by the University of Wisconsin-Milwaukee (June 30 July 3, 2013).

* Corresponding author at: 1 E Hanna St, Olin 258, DePauw University, Greencastle, IN 46135, USA. Tel.: + 1765721 0515; fax: +1 7656484766 .

E-mail address: pascallafontant@depauw.edu (P.J. Lafontant).

${ }^{1}$ Contributed equally to this paper.
}

(Kajstura et al.; Bergmann et al., 2009; Mollova et al., 2013) and mouse (Soonpaa and Field, 1997; Walsh et al., 2010; Senyo et al., 2013). However, the extent of inherent hyperplastic growth appears insufficient to support regeneration and recovery after significant loss of cardiac myocytes. Two main observations provide the basis for this limited regenerative capacity in adult mammals. The first is the apparent terminally differentiated state of ventricular cardiac myocytes past the neonatal stage, and their limited ability to proliferate. The second is the complex compensatory ventricular remodeling that cumulates in fibrosis and refractory scar formation which limits the regenerative potential.

Semi-aquatic and aquatic vertebrates such as newts (Bader and Oberpriller, 1979; Witman et al., 2011; Piatkowski et al., 2013), axolotls (Flink, 2002; Vargas-Gonzalez et al., 2005), and teleosts such as the zebrafish (Poss et al., 2002) and giant danio (Lafontant et al., 2012) have been studied as models for cardiac injury, repair, and regeneration. Unlike mammals, significant adult heart regeneration has been documented in these species. Ventricular myocardial regeneration is particularly robust in the zebrafish and the giant danio, two closely related fish species. Because of its genetic tractability, the zebrafish has become an important model for studying the molecular mechanisms 
orchestrating heart regeneration (Kikuchi and Poss, 2012). Following resection, or cryoinjury, or cautery injury, the zebrafish and the giant danio display the hallmarks of cardiac remodeling seen in adult mammals. However, an important distinction is the replenishment of the injured area by proliferating cardiac myocytes which mitigates the development of fibrosis and results in robust ventricular regeneration (Chablais et al., 2011; Gonzalez-Rosa et al., 2011; Schnabel et al., 2011). Despite these studies our understanding of the phylogenic distribution of heart regeneration in vertebrates remains incomplete. Both zebrafish and giant danio are minnows (Danioninae) that belong to the large and diverse cyprinid family of freshwater teleost fish (Meyer et al., 1993; Vidal et al., 2004). Whether heart regeneration is an attribute that extends beyond danionins to other members of the cyprinid family is not known.

The goldfish (Carassius auratus) is one of the most commonly kept aquarium fish species; it belongs to the true carp (Cyprininae) subfamily. The goldfish has historically served as an important model organism in physiological, behavioral, immunological and molecular evolutional studies (Ge et al., 1993; Hodgkinson et al., 2012; Huntingford, 2012). The goldfish can regenerate various organs and tissues including scale, fins, intramembranous bone, hair cells, optic nerve and spinal cord (Birnie, 1947; Caskey and O'Brien, 1948; Bernstein, 1964; Matsukawa et al., 2004; Smith et al., 2006; Thamamongood et al., 2012). The goldfish has also been used in cardiac physiology studies (Busselen, 1982; Ganim et al., 1998). Similar to the zebrafish (Hu et al., 2000) and giant danio, the goldfish possesses a type II heart that consists of a relatively thin vascularized compact heart and an extensive avascular spongy heart. However the ventricular morphologies of these fish are markedly different, with the zebrafish and giant danio having a more pyramidal shaped heart, while the goldfish displays a more saccular shaped heart, perhaps reflecting their specific ecological physiology. Exploring the link between ecological physiology and the regenerative potential of organs in closely related species is important because it may lend support to the concept of regeneration as an evolutionary variable (Brockes et al., 2001; Bely and Nyberg, 2010). The current study was designed to characterize the injury response of the common goldfish heart and ascertain its regenerative potential. The data show that despite displaying characteristics of early cardiac remodeling, the goldfish was able to regenerate its heart following cautery injury of a small portion of its ventricular myocardium.

\section{Material and method}

\subsection{Aminals}

Goldfish averaging $9.0 \mathrm{mg}$ in heart mass, $3.4 \mathrm{~g}$ in body mass and $46.8 \mathrm{~mm}$ in standard length were obtained from a local provider, and maintained in $40 \mathrm{~L}$ tanks, with 10 to 15 fish per tank, at $25{ }^{\circ} \mathrm{C}$ on $14 / 10 \mathrm{~h}$ day/night cycles for two to three weeks prior to experiments. Experimental procedures were approved by the Committee for the Care and Use of Laboratory Animals at DePauw University.

\subsection{Surgery and ventricular cautery}

These procedures were previously described (Lafontant et al., 2012). Briefly, goldfish were anesthetized with $0.02 \%$ MS Tricaine for one to two minutes and placed ventral side up in a slit cut in a wet rectangularshaped sponge block. Using a Leica ZOOM 2000 dissecting microscope (Leica Microsystems, Bannockburn, IL, USA) a pair of fine forceps was used to remove the scales above the thoracic cage; then the skin and the pectoral muscles were gently dissected midline, and occasionally fine scissors where used to create a 4 to $5 \mathrm{~mm}$ opening that revealed the beating heart. The ventricular apex could not be easily and consistently identified in situ. Conversely the base of the bulbus that could be easily located throughout the cardiac cycle, because of its prominence and its translucency, was used as a guide to target the ventral aspect of the ventricle. In one set of studies a nichrome wire with a flat tip $0.455 \mathrm{~mm}$ diameter (24 gauge) was used to create a relatively small injury. In another set of experiments the nichrome wire was bent to increase the area of contact with the ventricular tissue to achieve approximately twice the size an injury. In both sets of experiments the wire was heated on an open flame Bunsen burner for $5 \mathrm{~s}$, and left to cool for $3 \mathrm{~s}$, then the tip of the wire was gently applied to the ventricular myocardium and left to cool for an additional 3 to $5 \mathrm{~s}$ before removal from the heart surface. The fish were returned to a new freshwater tank. Control fish $(\mathrm{n}=17)$ and injured fish were sacrificed at $1,3,7$, $14,21,30$, and 45 days ( $\mathrm{n}=9,18,28,17,11,4,14$, respectively) using $0.2 \%$ MS Tricaine. Once all body and opercula movements had ceased, the heart was removed by grasping and pulling the aorta proximal to the bulbus arteriosus. Heart weight, body weight and standard length were measured prior to further processing, except for ex-vivo cell cycle studies, and immunohistochemistry when the hearts were transferred directly into a $30 \%$ sucrose (Sigma-Aldrich, St Louis, MO, USA) solution for cryoprotection and later fixation.

\subsection{Measurements and characterization of injury by histochemistry}

The hearts were removed and fixed in $4 \%$ paraformaldehyde at $4{ }^{\circ} \mathrm{C}$ overnight. The next day the hearts were cryoprotected in $30 \%$ sucrose, and placed in 13-mm diameter aluminum seal cups (Wheaton, Millville, NJ, USA), that were then filled with freezing medium (Tissue-Tek OCT, Torrance, CA, USA) and kept at $-80{ }^{\circ} \mathrm{C}$ prior to sectioning. The hearts were exhaustively sectioned sagittally on a Leica CM 1900 cryostat (Leica Microsystems, Bannockburn, IL, USA). Sections from the middle of each heart were then stained and analyzed.

To assess the amount connective tissue indicative of the injury size at 7, 14 and 45 days, $10 \mu \mathrm{m}$ sections from the middle of the heart were stained with fast green and picrosirius red. Sections were observed on a Nikon SMZ 1000 dissecting microscope (Nikon Instruments Inc., Melville, NY, USA) equipped with a Spot Insight QE camera (Diagnostic Instruments Inc., Sterling Heights, MI, USA). Images were projected on a Dell 17-inch monitor and overlaid with a $20 \mathrm{~mm} \times 15 \mathrm{~mm}$ pointcounting grid $(20 \times 14$ point-intercepts $)$ with 280 equidistant pointintercepts. Using the point-counting method the fraction of point intercepts landing randomly on connective tissue (pale green and red) and myocardial tissue (green) was calculated and expressed as volume density (\%).

To assess the deposition of collagen, Masson's trichrome staining was performed according to the manufacturer's protocol (SigmaAldrich) with some modifications. Briefly, slides were rinsed in deionized water and incubated in preheated Bouin's solution at room temperature overnight. Slides were stained with acid hematoxylin solution for $5 \mathrm{~min}$, and then washed in running tap water for $12 \mathrm{~min}$. Next they were stained in $0.1 \%$ Biebrich scarlet- $0.1 \%$ acid fuchsin in 1\% acetic acid for $5 \mathrm{~min}$, and then incubated in 10\% phosphotungstic-phosphomolybdic acid solution for $5 \mathrm{~min}$, then in $2.4 \%$ aniline blue solution for $5 \mathrm{~min}$, followed by $1 \%$ acetic acid. Slides were dehydrated through graded alcohol, cleared in xylene and mounted using Permount Mounting Medium (Electron Microscopy Sciences, Hatsfield, PA, USA). Stained sections were visualized and imaged on a Nikon Optiphot (Nikon Instruments Inc.).

\subsection{Characterization of injury and regeneration in plastic section and by transmission and scanning electron microscopy}

For studies of the myocardium in plastic sections and by transmission electron microcopy, hearts were fixed in $2.5 \%$ fresh glutaraldehyde in $100 \mathrm{mM}$ cacodylate buffer overnight at $4{ }^{\circ} \mathrm{C}$. The hearts were washed the next day in cacodylate buffer and stored at $4{ }^{\circ} \mathrm{C}$ for later processing. Hearts were post-fixed in $1 \%$ tannic acid and transferred to $1 \%$ osmium tetroxide and then embedded in EMbed-812 Resin (Electron Microscopy Sciences, Hatsfield, PA, USA) following dehydration in acetone. Two- 
micron sagittal sections were cut and stained with Toluidine Blue $\mathrm{O}$ for light microscopy analysis. For electron microscopy analysis, ultra-thin sections $100 \mathrm{~nm}$ thick were cut, set on a single slot or 200-mesh copper or nickel grids and imaged on a Tecnai G2 Spirit BioTWIN electron microscope (FEI Company, Hillsboro, OR, USA).

For scanning electron microscopy the hearts were fixed in $2.5 \%$ fresh glutaraldehyde in $100 \mathrm{mM}$ cacodylate buffer overnight at $4{ }^{\circ} \mathrm{C}$. The
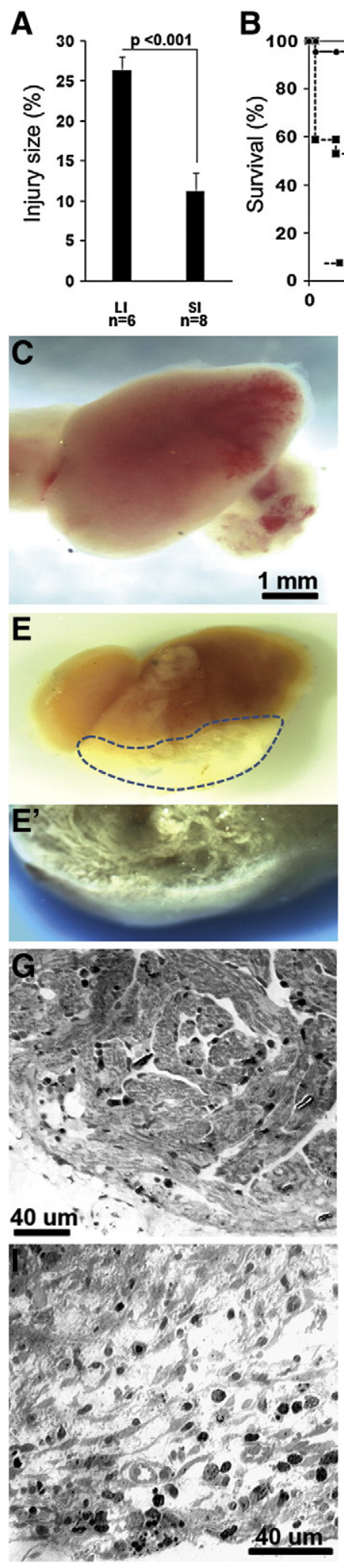
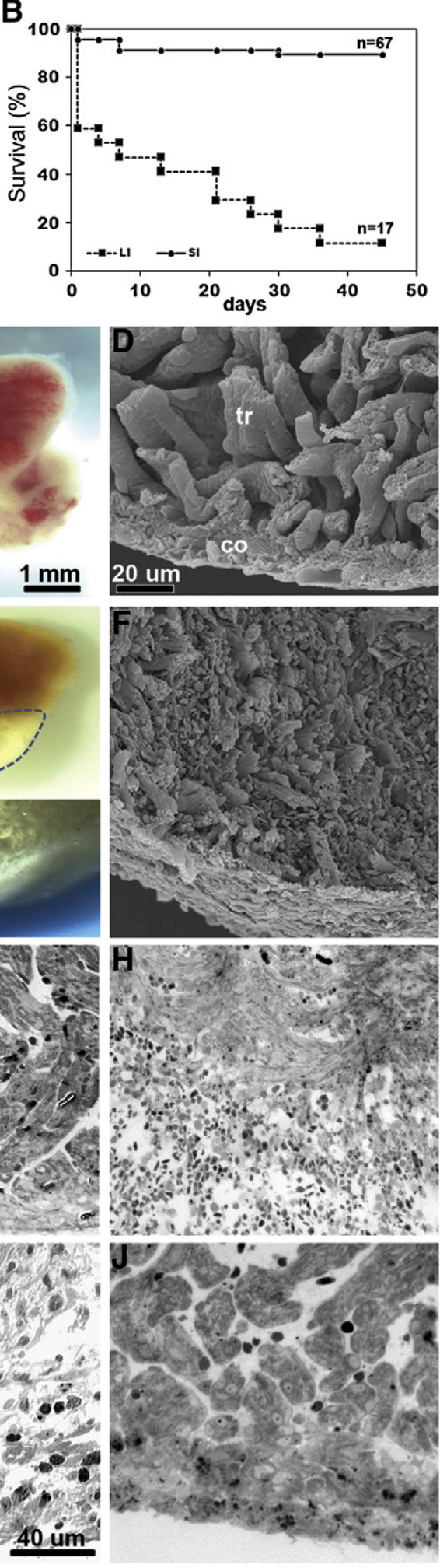

hearts were washed the next day in cacodylate buffer sectioned sagittally and dehydrated in alcohol gradients. Alcohol was then substituted with increasing concentrations of hexamethyldisilizane (HMDS, Sigma-Aldrich) in alcohol in a fume hood. After three exchanges in 100\% HMDS, the hearts were allowed to dry overnight before coating with $80 \%$ palladium-20\% gold using a Polaron E5100 sputter coater (Quorum Technologies Ltd, UK) and imaged on a JEOL 5800LV at $15 \mathrm{kV}$ (JEOL USA, Peabody, MA, USA).

\subsection{Histochemical detection of inflammatory and endothelial cells}

Cryosections $10 \mu \mathrm{m}$ thick were stained for the detection of inflammatory activity using Peroxidase (Myeloperoxidase) Leukocyte Kit, according to the manufacturer's protocol (Sigma-Aldrich). Briefly, slides were washed in gently running tap water and allowed to air dry in the dark. One vial of peroxidase indicator reagent and $200 \mu \mathrm{L}$ of $3 \%$ hydrogen peroxide were added to $50 \mathrm{~mL}$ pre-warmed trizmal buffer. The slides were incubated in the peroxidase indicator reagent solution for $30 \mathrm{~min}$ in the dark at the $37{ }^{\circ} \mathrm{C}$. Following incubation, the slides were washed in gently running tap water for 15-30 s and allowed to air dry. The slides were counterstained with eosin, dehydrated in an alcoholxylene series, air-dried and coverslipped using Permount. MPO positive cells were enumerated in two to three fields from 3 sections of each heart at $20 \times$ and averaged. For histochemical detection of endothelial cells, $10 \mu \mathrm{m}$ sections were stained with FITC-labeled Bandeiraea simplicifolia (BS) lectin (Sigma-Aldrich) in Hepes buffer (10 mM Hepes, $0.15 \mathrm{M} \mathrm{NaCl}, 0.1 \mathrm{M} \mathrm{CaCl}_{2}$, $\mathrm{pH} 7.5$ ), overnight. Sections were washed the next day and cell nuclei where stained with Hoechst stain (Invitrogen, Eugene, OR, USA) prior to visualization.

\subsection{Cell cycle activity by 5-ethynyl-2-deoxiuridine incorporation and identification of cardiac myocytes}

In order to identify heart cells that have entered the cell cycle and progressed to S-phase, we studied the incorporation of 5-ethynyl-2deoxyuridine (EdU) using the Click-iT EdU kit (Invitrogen-Molecular Probes, Eugene, OR, USA). EdU was diluted in L-15 Leibovitz media without serum (Hyclone, Logan, UT, USA). Each experimental and control heart was excised and transferred into $400 \mu \mathrm{L}$ of EdU solution $(50 \mu \mathrm{M})$ in a 96 well plate pre-warmed at $25{ }^{\circ} \mathrm{C}$ in an incubator. After six hours in the incubator the hearts were removed from the L-15 Leibovitz solution containing EdU, washed in PBS and fixed in FAethanol. EdU detection was performed on $10 \mu \mathrm{m}$ thick sagittal sections following the manufacturer's protocol and was visualized with Alexa Fluor 647. For cardiac myocytes identification following Click-iT EdU reaction, sections were immunoreacted overnight with anti-myosin heavy chain-1 (MYH1) antibody (Santa Cruz Biotechnology Inc., Santa Cruz, CA, USA), followed by FITC conjugated anti-mouse secondary antibody (Sigma-Aldrich). Lastly, sections were also stained with Hoechst and coverslipped using PermaFluor mounting media (Thermo Scientific, Fremont, CA, USA), visualized and imaged on a Nikon Optiphot (Nikon

Fig. 1. Reconstitution of goldfish ventricle following cautery injury. A set of small injury (SI) and large injury (LI) were produced in the goldfish ventricle (A); subset measured at $24 \mathrm{~h}$. $\mathrm{LI}$ resulted in low survival rate in contrast to the high survival rate in SI (B). Gross morphology of goldfish heart ex vivo (C), and scanning electron micrograph (D) of uninjured sagittally sectioned heart showing intact compact heart (co) and trabeculae (tr). Gross appearance of the goldfish ventricle (E) with injury highlighted by dashed ellipsoid, and of a sagittally sectioned heart ( $\left.E^{\prime}\right)$ one day post-cautery injury (dpci). Scanning electron micrograph of sagittally sectioned injured ventricle showing a complete loss of compact cardiac myocytes and trabeculae in the injured area (F). Representative plastic sections of the ventral aspect of uninjured heart $(G)$ with intact compact and spongy myocardium, in plastic section of seven days heart after injury $(\mathrm{H})$ with the border zone on the upper right, and necrotic injured area on the lower right, with absence of myocardial tissue, and high density of nuclei. Plastic sections of injured ventricle $14 \mathrm{dpci}$ (I) showing granulation tissue with the presence of new cells and extracellular matrix, and plastic section on injured area $30 \mathrm{dpci}(\mathrm{J})$ with myocardial tissue approximating the uninjured ventricle. 
Instruments Inc.). EdU incorporation was estimated using two to three fields in a middle section under a $20 \times$ objective.

\subsection{Statistical analysis}

Data are means and \pm S.E.M. statistical analysis included one way ANOVA followed by Student-Newman-Keuls post-test (Figs. 2 and 3) and Student's t-test (Figs. 1 and 7). Differences were considered significant at $\mathrm{p} \leq 0.05$.

\section{Results}

3.1. Morphological characteristic of wound repair in the goldfish myocardium

Cauterization of the goldfish heart leads to myocardial tissue loss of approximately one ninth of the ventricle which resulted in a $90 \%$ survival rate. However cauterizing injury to achieve myocardial tissue loss comparable to that reported in zebrafish and giant danio (20-25\%) resulted in markedly low survival rate (Fig. 1A, B). Thus we studied the repair response to small injuries in the goldfish heart. The uninjured goldfish heart appeared more saccular and less pyramidal than the zebrafish and giant danio (Fig. 1C). Scanning electron microscopy (SEM) showed the expected thin compact heart and the extensive trabeculation of the spongy heart of the goldfish ventricular chamber (Fig. 1D). Cauterization of the ventral aspect of the ventricle resulted in thermal ablation of the region (Fig. 1E, E'). SEM studies confirmed extensive damage to the compact heart, the adjacent trabeculae of the spongy heart, as well as the loss of the intact myocardial tissue pattern (Fig. 1F).

Histologic observation of the heart in uninjured control and at 7, 14, 30 days post-cautery injury (dpci) showed progression of wound repair and the progressive emergence of new myocardial tissue in the injured area. More specifically, while the uninjured heart displayed an intact compact and spongy heart (Fig. $1 \mathrm{G}$ ), at $7 \mathrm{dpci}$, the injured area consisted of necrotic tissue, with a clear border zone separating the distal injury area from the adjacent proximal cardiac myocytes of the spongy heart (Fig. 1H). This clear border zone was also observed by SEM (not shown). Through the first week, the injured area was devoid of clearly identifiable cardiac myocytes; instead it consisted primarily of amorphous tissue infiltrated by numerous inflammatory cells. By 14 dpci however, the site of injury appeared to be populated by a mixture of non-myocyte and myocyte cell profiles (Fig. 1I). By $30 \mathrm{dpci}$ the previously injured compact and spongy heart appeared mostly reconstituted (Fig. 1J). To further evaluate the repair response and estimate the injury size up to $45 \mathrm{dpci}$, volume densities were determined for the connective tissue using fast-green and picrosirius red stained cryosections. There was little connective tissue in the uninjured heart (Fig. 2A). The connective tissue area which occupied $13 \%$ of the ventricle by 7 dpci (Fig. 2B), decreased to $9 \%$ by 14 dpci (Fig. 2C), and $3 \%$ by 45 dpci (Fig. 2D). The connective tissue was progressively resorbed (Fig. 2E) and appeared to be replaced by myocardial tissue, suggesting the goldfish in addition to possessing the ability to repair ventricular tissue may also be able to reconstitute small portions of its ventricular myocardium.

\subsection{Inflammatory response in the injured goldfish myocardium}

Inflammatory cells infiltrated not only the injury area but also the border zone of the injury. Heterophils displaying phenotypes of activation and migration could be seen adjacent to and in direct contact with border zone endocardium (Fig. 3A, B). To ascertain the extent and progression of the inflammatory response, myeloperoxidase (MPO) positive cells in the control and injured hearts were quantified. The uninjured goldfish heart contained few MPO-positive cells in the ventricular lumen or the vessels of the compact heart (Fig. 3C). However
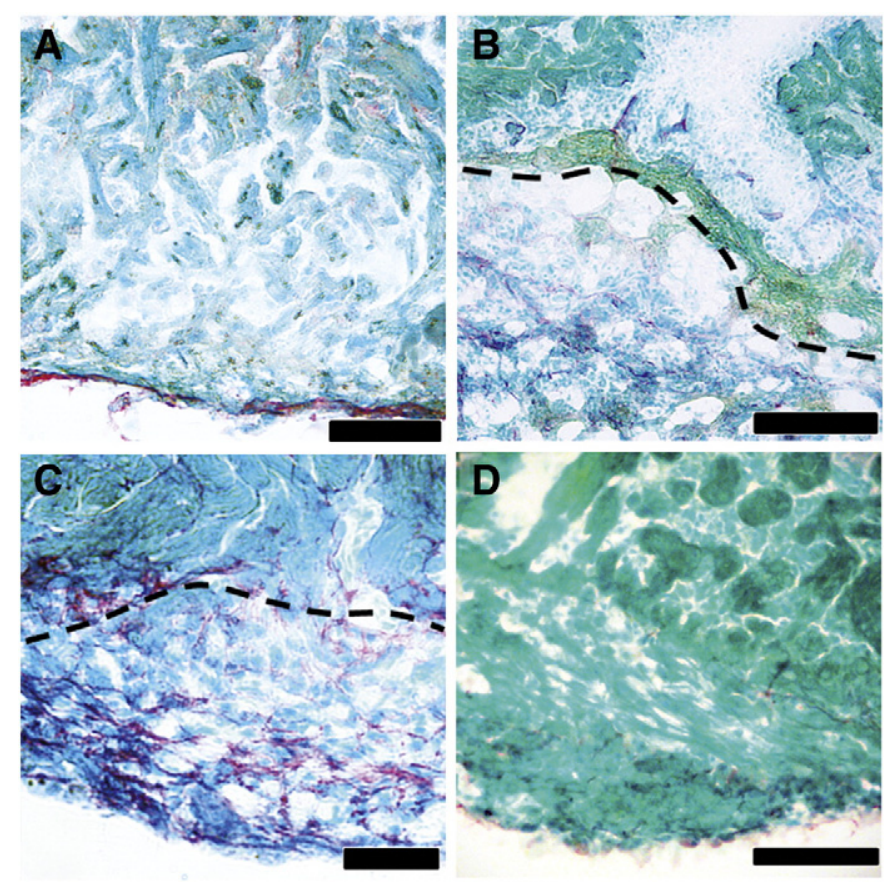

E

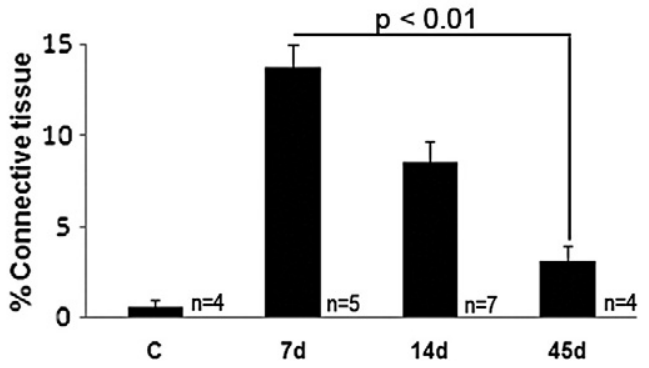

Fig. 2. Regression of connective tissue and replenishment of myocardial tissue in the goldfish heart. Representative fast green and picrosirius red section of uninjured hearts (A) containing myocardial tissue with structurally intact compact and trabeculae structure. At $7 \mathrm{dpci}(\mathrm{B})$, stained section with connective tissue (pale green) occupying the injured area; the dashed line delineates the border between injured (below) and non-injured areas (above). At $14 \mathrm{dpci}(\mathrm{C})$ injured area (below line) consisting primarily of cellularized connective tissue (pale green) and fine extracellular filamentous fibers (red). At $45 \mathrm{dpci}$ (D) section with further regression of connective tissue and reconstitution of the compact heart and of trabeculae. Volume density of the connective tissue (E) in the injured heart. (Scale bar, $50 \mu \mathrm{m}$ ). Please refer to the web version of this article for interpretation of references to color in the figure legend.

by 3 dpci a significant number of MPO-positive inflammatory cells had accumulated within the injured area (Fig. 3D). The number of MPOpositive cells was markedly decreased at $14 \mathrm{dpci}$ (Fig. E), and had returned to baseline levels at $45 \mathrm{dpci}$ (Fig. 3F), suggesting the inflammatory response had subsided (Fig. 3G).

Since MPO may identify different subsets of inflammatory cells, the phenotypic diversity of this cell population was determined. In addition to heterophils and macrophages, numerous inflammatory cells with phenotypic characteristics of melanomacrophages could be identified at $14 \mathrm{dpci}$ (Fig. 4A). Transmission electron microcopy (TEM) confirmed that these melanomacrophages were present within the repairing tissue and in adjacent lacunae between trabeculae (Fig. 4B). These cells contained electron dense granules and were also found in close apposition to the endocardial cell lining, suggestive of an adhesive interaction (Fig. 4C, $\mathrm{C}^{\prime}$ ).

\subsection{Angiogenesis in the injured goldfish myocardium}

FITC-labeled Bandeiraea simplicifolia (BS)-lectin binding in the goldfish ventricle was used in an attempt to ascertain and quantify a possible angiogenic response in the heart following the injury. In 


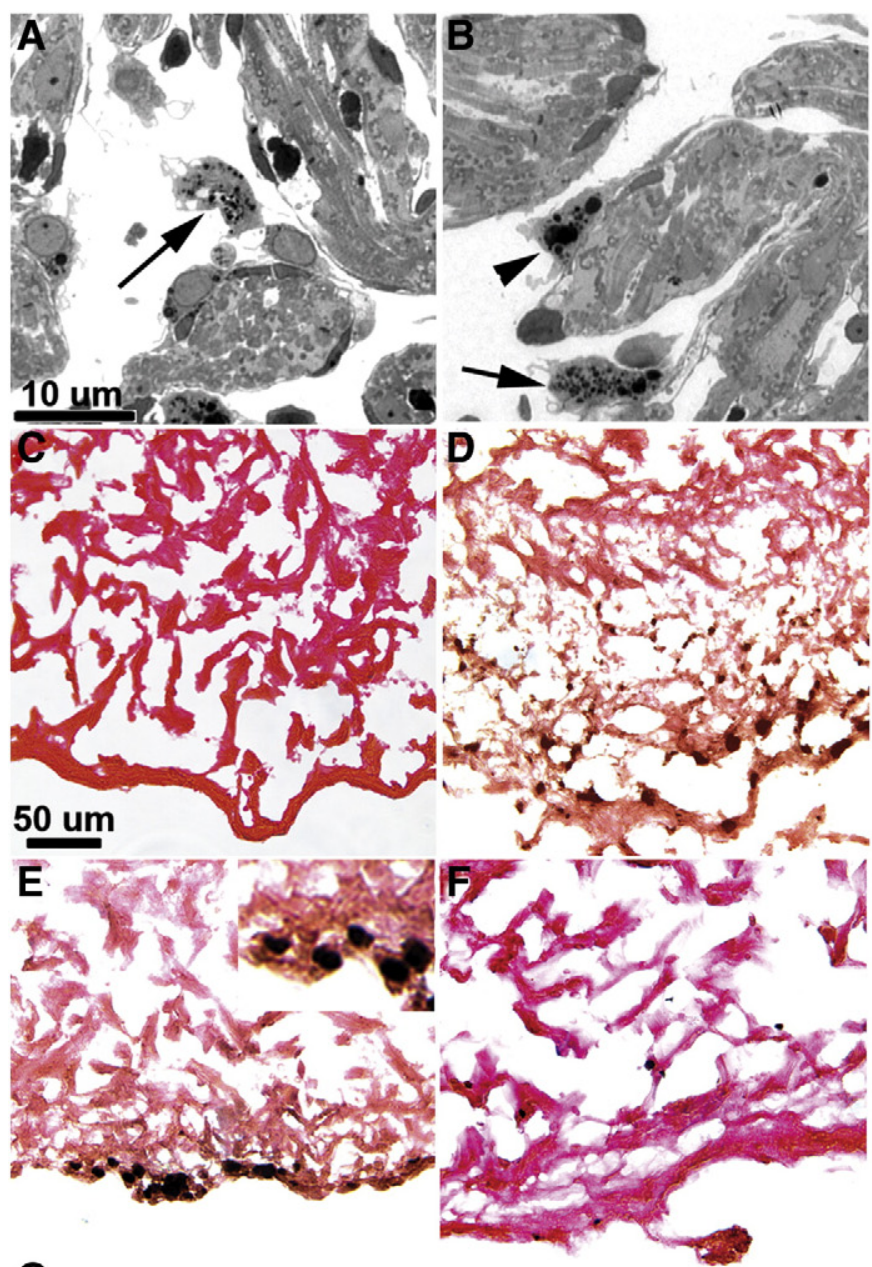

G

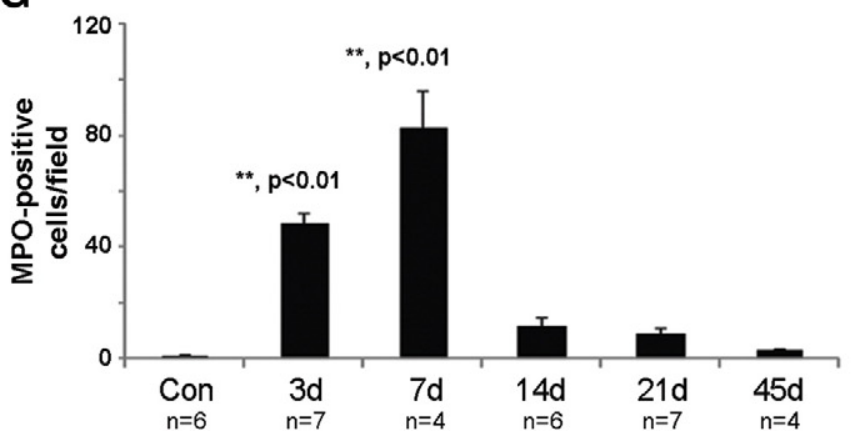

Fig. 3. Inflammation in the cauterized goldfish heart. Representative plastic section micrographs of inflammatory cells in the injury border zone $24 \mathrm{~h}$ post-injury showing an activated heterophil (A, arrow) in the lumen, another heterophil (B, arrow) and another ( $\mathrm{B}$, arrowhead) adhering to the endocardium. Myeloperoxidase (MPO) reactivity in inflammatory cells (black) in control heart section (C), at $7 \mathrm{dpci}(\mathrm{D}), 14 \mathrm{dpci}(\mathrm{E})$, and $45 \mathrm{dpci}(\mathrm{F})$. Kinetics of MPO-positive cells infiltrating the injured goldfish heart (G).

control ventricles, lectin binding was relatively low and primarily associated with endocardial cells lining the borders of the luminal trabeculae. Compact heart endothelial cells were also poorly labeled, as a result compact heart capillaries could not be observed (Fig. 5A). At 7 and 14 dpci lectin binding increased in the area of injury, but the patchy nature of the binding prevented the identification of the cellular source of fluorescence (Fig. 5B, C). However, by 14 dpci, capillaries were readily observed in the repairing heart (Fig. 5D), as well as in sections prepared for TEM (Fig. 5E). These findings are consistent with a robust angiogenic response in the repairing goldfish ventricle.

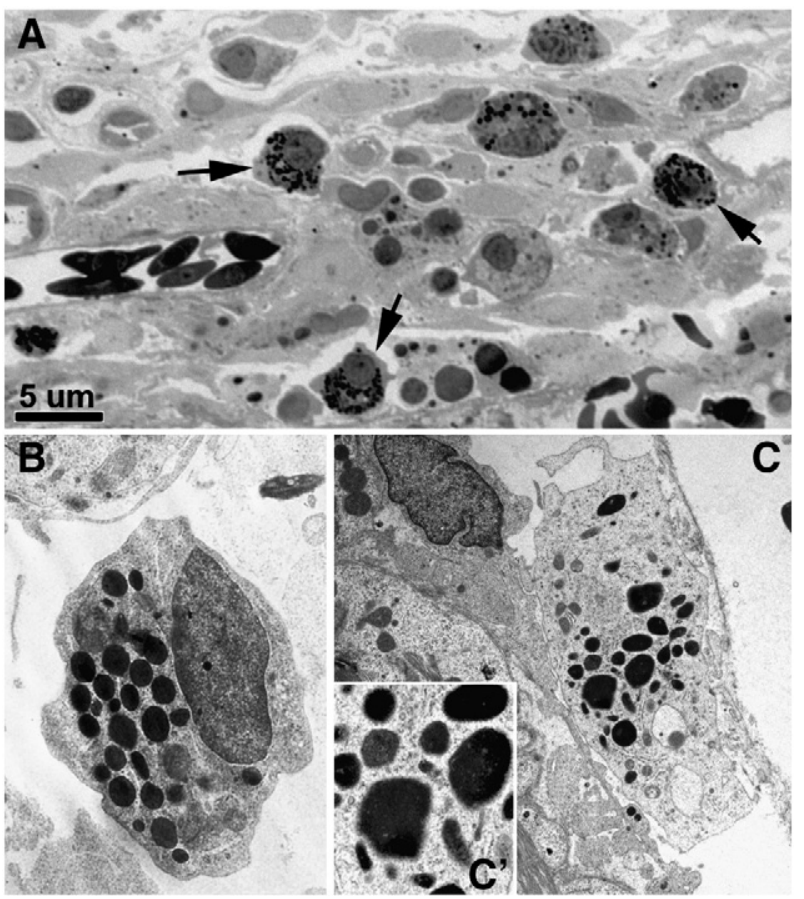

Fig. 4. Melanomacrophages in the cauterized goldfish ventricle. Representative images of toluidine blue stained area of goldfish ventricle at $14 \mathrm{dpci}(\mathrm{A})$ infiltrated with numerous inflammatory cells with phenotypic characteristics of melanomacrophages (MM, arrows). TEM of a MM (B) in the injured area interstitium of goldfish ventricle 14 dpci. TEM of a MM attached to the endocardium in the border zone of the injury ( $C, C^{\prime}$-higher magnification of round electron dense granules).

\subsection{Collagen accumulation and structure in the repairing myocardium}

To determine the extent of collagen accumulation in the injured ventricle sections spanning the course of repair were collected and stained with Masson's trichrome. In the uninjured heart the presence of collagen fibers was minimal (Fig. 6A). Aniline blue-stained filamentous collagen fibers were evident within the connective tissue of the injured area. While collagen staining was diffuse at 7 dpci (Fig. 6B, $\mathrm{B}^{\prime}$ ), the filamentous nature of the collagen and the increased level of organization were more apparent at $14 \mathrm{dpci}$ (Fig. 6C, $\mathrm{C}^{\prime}$ ). The decrease in collagen staining paralleled the regression in connective tissue and the reconstitution of the cardiac myocardium. TEM at 14 days confirmed the presence of ordered but sparse filamentous collagen bundles (Fig. 6D) and the presence of numerous fibroblasts (Fig. 6E) within the injured area. The fibroblasts displayed abundant rough endoplasmic reticulum membranes consistent with the interpretation that these cells were actively engaged in protein synthesis (Fig. 6F).

\subsection{Cardiac myocytes and cell cycle activity in the repairing goldfish myocardium}

The reconstitution of the lost myocardial tissue suggests the goldfish possesses a regenerative capacity in the heart. To determine whether cell cycle activity underlies this ability, ethynyl deoxyuridine (EdU) incorporation was evaluated in the goldfish myocardium. EdU incorporation in cell nuclei was relatively low in control ventricles (Fig. 7A), and was increased in the injury area at 3 dpci (Fig. 7B), 7 dpci (Fig. 7C), and at $14 \mathrm{dpci}$ (Fig. 7D). EdU-positive nuclei could be found throughout the injured area, and within the boundaries of MYH1 stained cells (Fig. $7 \mathrm{C}^{\prime}$ and $\mathrm{D}^{\prime}$ ). EdU incorporation in all cells increased approximately 4-fold at $14 \mathrm{dpci}$ as compared to control (Fig. E), while EdU incorporation in nuclei of MYH1-positive cardiac myocytes increased approximately 


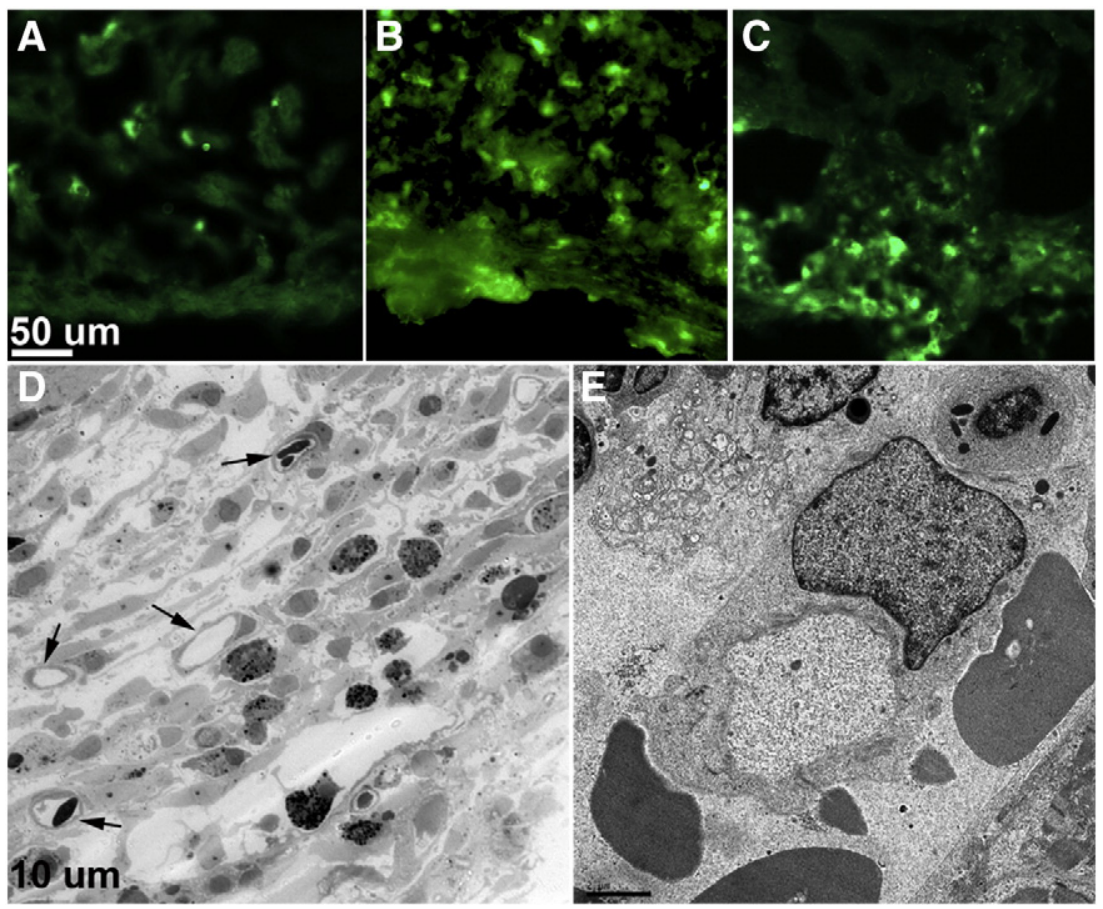

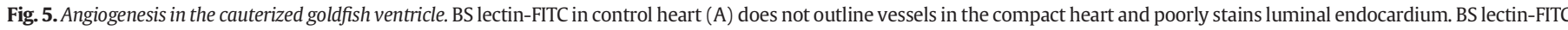

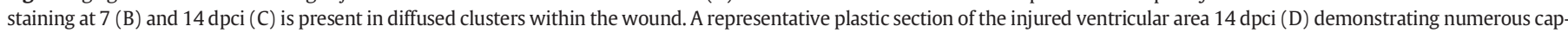
illary profiles (arrows). A capillary profile at $14 \mathrm{dpci}$ within the injured area visualized by TEM (E).

two-fold (F). Attempt at further identifying cardiac myocytes nuclei with myocyte enhancer factor-2C (MEF-2C) antibody using a variety of protocols was unsuccessful (data not shown). EdU incorporation in cell nuclei with weak MYH1 cytoplasmic immunoreactivity was also observed in the repairing heart particularly at $14 \mathrm{dpci}$, suggesting the possibility of de-differentiated or partially differentiated cardiac myocytes contributing to the reconstitution of the injured ventricle. Ultrastructural characteristics of the repairing heart at $14 \mathrm{dpci}$ revealed
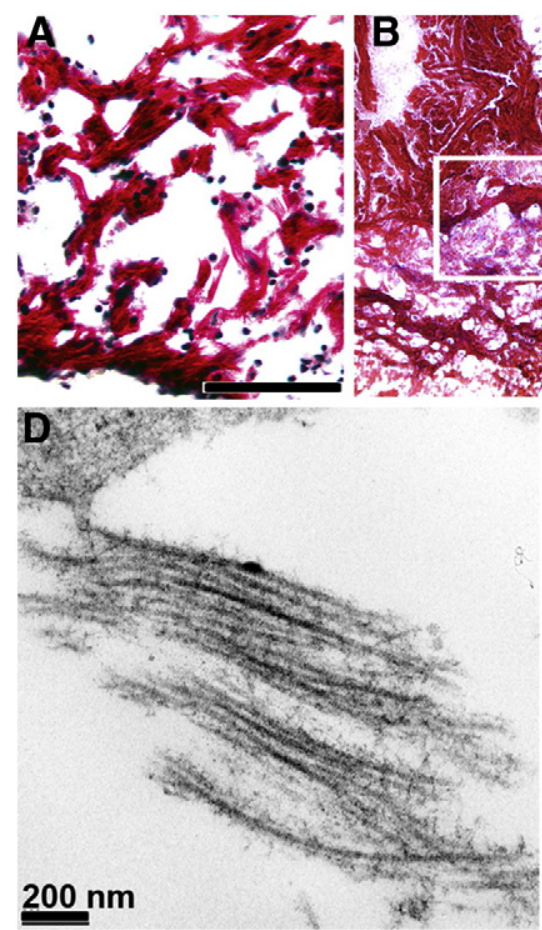
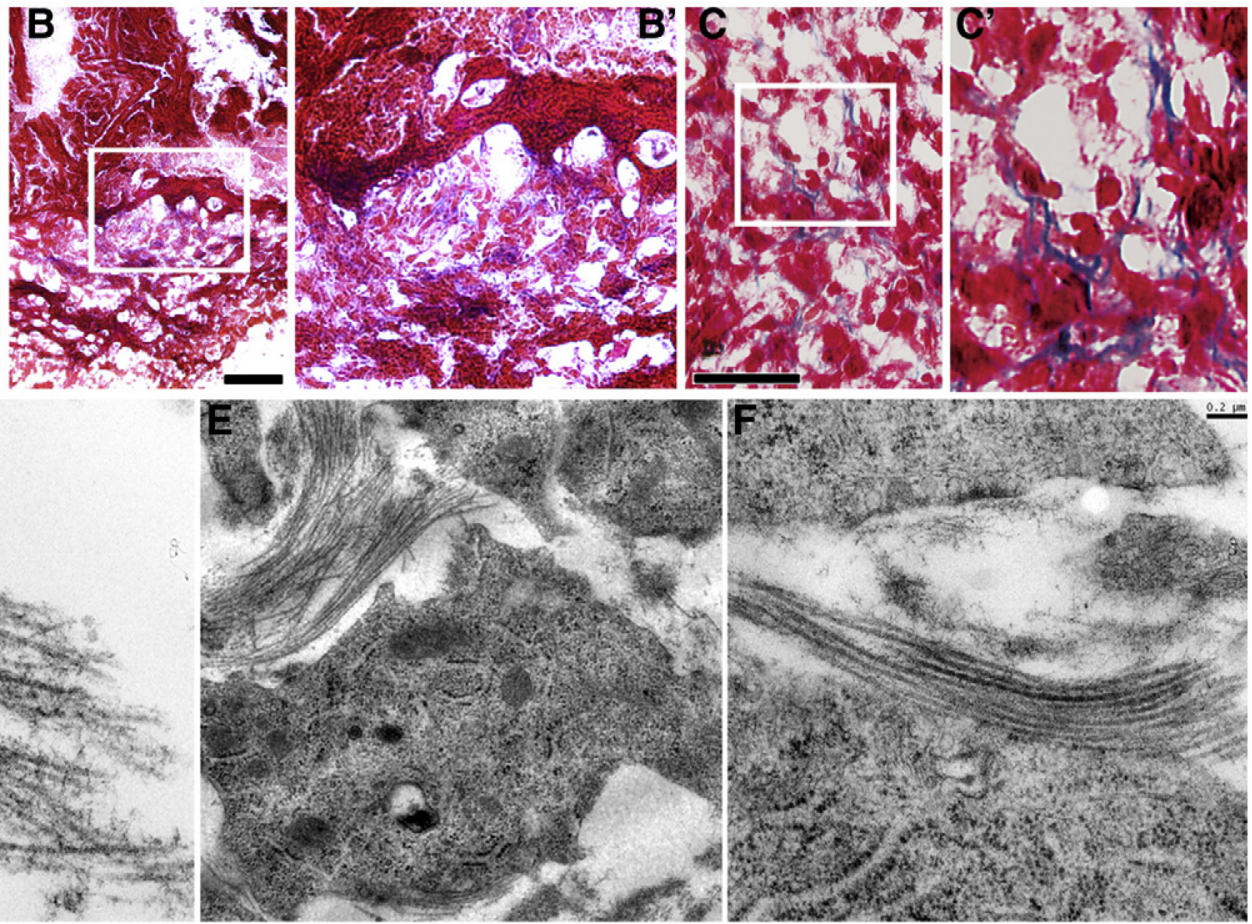

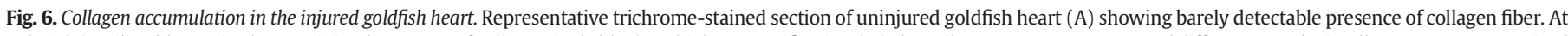

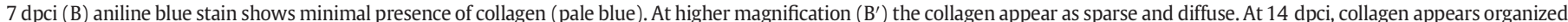

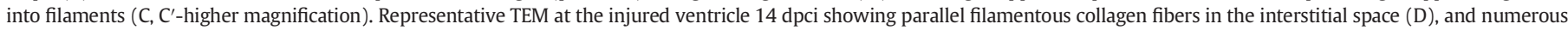

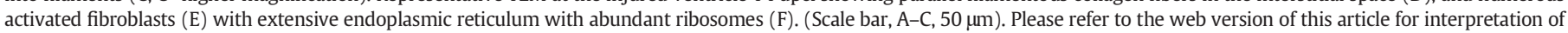
references to color in the figure legend. 

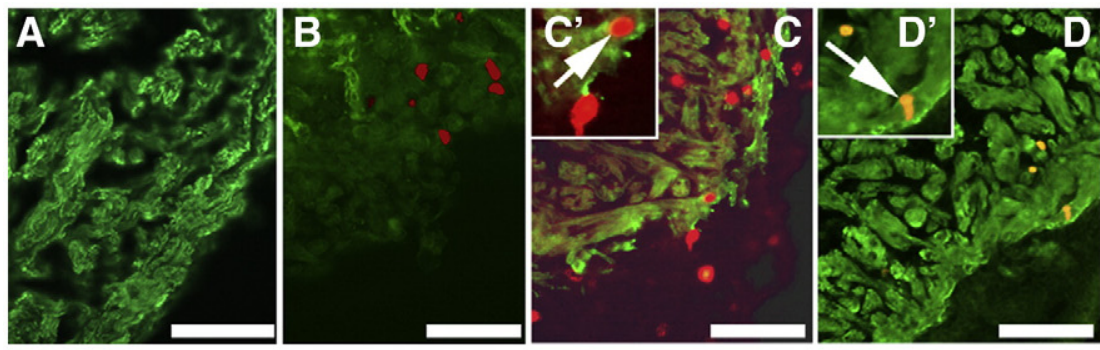

$\mathbf{E}$
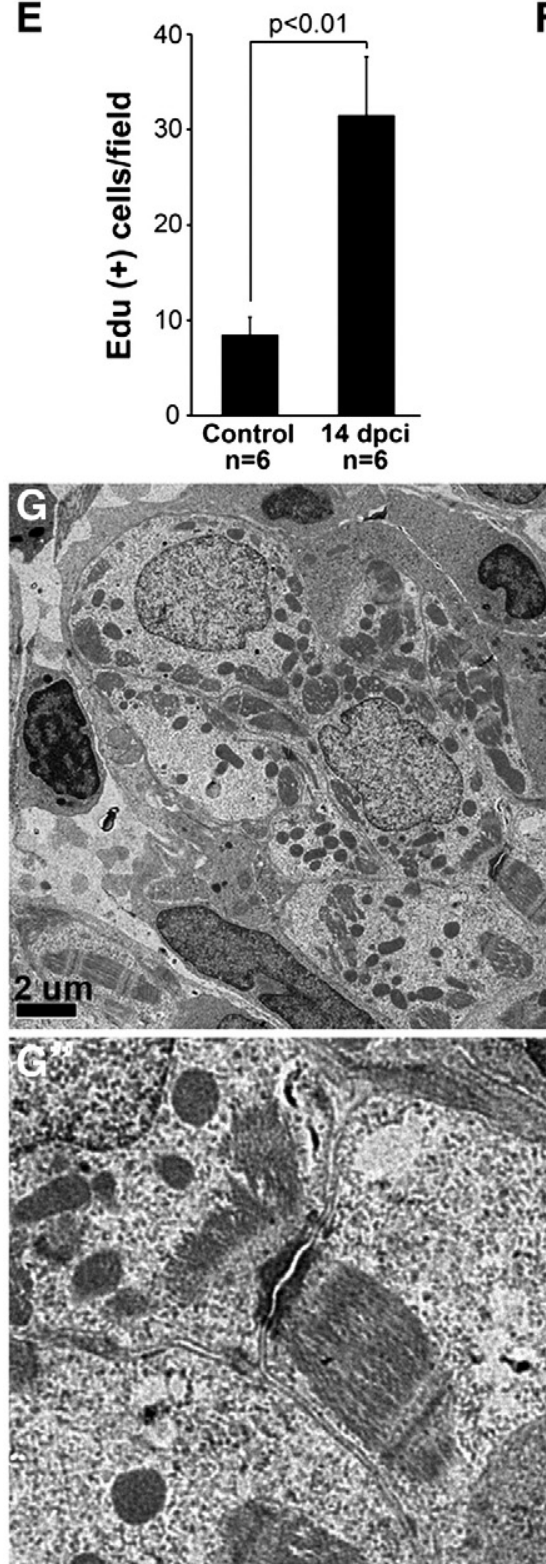

$\mathbf{F}$

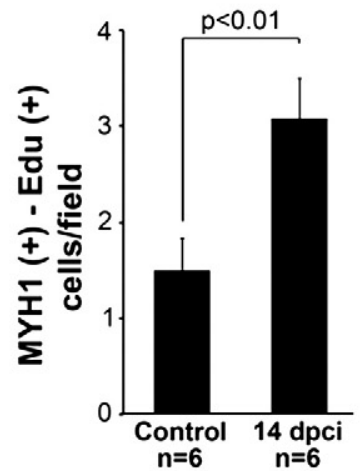

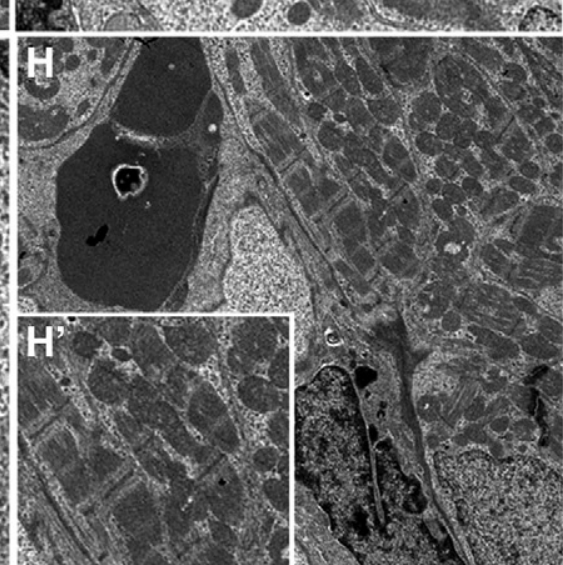

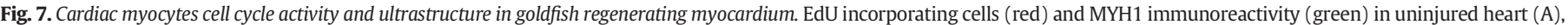

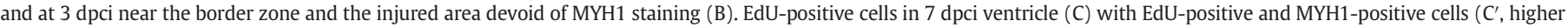

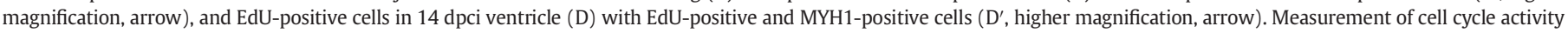

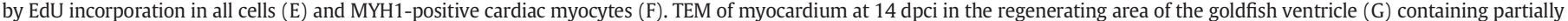

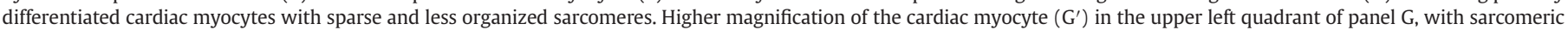

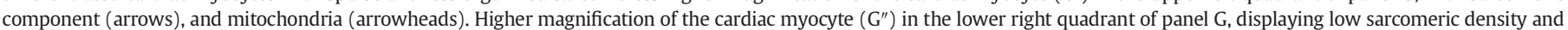

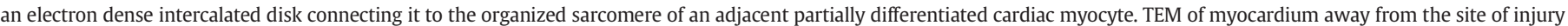

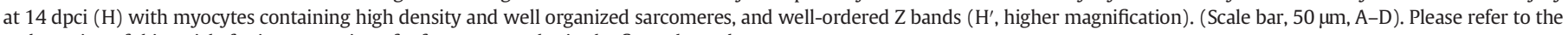
web version of this article for interpretation of references to color in the figure legend.

a population of cardiac myocytes with marked reduction in actin myosin filaments, and less organized sarcomeres (Fig. 7G, $G^{\prime}, G^{\prime \prime}$ ). The phenotype of these myocytes was in contrast to those with abundant and well organized sarcomeres found in uninjured heart or in cardiac myocytes distal to the injury in the cauterized heart (Fig. $7 \mathrm{H}, \mathrm{H}^{\prime}$ ). These observations were consistent with the notion that the ongoing 
replenishment of myocardial tissue was attributable in part to the reappearance of cardiac myocytes albeit of a lesser differentiated phenotypes.

\section{Discussion}

This study establishes that myocardial regenerative capacity, albeit less robust than that reported in the zebrafish and the giant danio, is nonetheless present in the goldfish ventricle; hence, cardiac regenerative ability extends beyond the danionins, and into the diverse family of cyprinids. It also demonstrates the cellular basis for ventricular regeneration is analogous to that seen in other fish, where reconstitution of resected or ablated myocardial tissue is supported by partially differentiated or dedifferentiated cardiac myocytes. Moreover, the early and intermediate responses to the injury involve inflammation, collagen accumulation and angiogenesis, and these processes are orchestrated in a manner that supports or permits regeneration.

In the goldfish, injuries were produced on the ventral aspect of the ventricle as opposed to the injuries in the danios where the pyramidal morphology of the ventricles facilitates targeting of the apical region (Poss et al., 2002; Raya et al., 2003; Lafontant et al., 2012). In our hands the more saccular appearance of the goldfish ventricle in vivo made the targeting of the apical region challenging. Moreover our attempt at producing injury sizes comparable to that achieved in the zebrafish and giant danio resulted in remarkably low survival. As a result, we were limited to relatively small injuries that were exacted at the mid-ventral aspect of the ventricle. Whether the location and/or the extent of injury were responsible for the low survival rate in larger injuries could not be ascertained.

The ventricular morphology of fish ventricles reflects their particular functional characteristics and ecological physiology (Cimini et al., 1977; Greco and Tota, 1981; Santer, 1985; Agnisola and Tota, 1994). For example, the thickness of the compact heart in fish not only correlates with age, but also with the level of natural activity or athleticism of the fish. Indeed, fish with pyramidal shaped ventricles display higher active physical activity than fish with saccular ventricles. A recent study in the goldfish concluded that its ventricle performs as a volume rather than a pressure pump, and that the goldfish may have limited cardiac functional reserve capacity (Garofalo et al., 2012). A comparative agematched or developmentally-matched study of cardiac performance in these fish has not been reported. However based on our observations, we speculate that the inability of the goldfish to sustain injuries of similar magnitude as the zebrafish and giant danio may be related to lesser cardiac functional reserve compared to the danios.

In our studies, cauterization produced an area of necrosis that elicited inflammatory cell recruitment, collagen deposition and neovascularization during repair and regeneration. These three temporally overlapping processes were previously documented in the giant danio (Lafontant et al., 2012), and in part noted in zebrafish (Lien et al., 2006; Parente et al., 2013). The effect of inflammation in fish heart regeneration is unclear although a recent report in the zebrafish showed the attenuation of the inflammatory response by glucocorticoids was coupled with impaired cardiac repair and regeneration (Huang et al., 2013). The robust inflammatory response in the goldfish involves inflammatory cell infiltrations of various subtypes into the necrotic injury site, as well as adjacent myocardial areas that were not directly injured. The subtypes include heterophils, macrophages, and a population of melanomacrophages. The presence of melanomacrophages has not been reported in the zebrafish, giant danio, or the goldfish heart. However, in the goldfish kidney and spleen they act as phagocytes (Herraez and Zapata, 1986, 1991). It had been suggested that their melanin-containing granules decrease oxidative stress by contributing to neutralization of reactive oxygen species (Zuasti et al., 1989). Melanomacrophages also play a key role in the process of tail resorption in tadpoles during metamorphosis (Divya et al., 2010). The presence of melanomacrophages in the goldfish heart during repair and regeneration suggests an important role in injury response and cardiac remodeling in this species. Whether the presence of these cells and their involvement in repair and regeneration is observed in other fish species warrants further study.

Within the temporal window explored, the accumulation of connective tissue and collagen, and the emergence of vessels in the wounded area, appears to be concurrent. Collagen and other extracellular matrix proteins provide not only a scaffold for the reconstruction of myocardial tissue, but they also act as a substrate that defines the mechanical properties of the wound as well as providing cryptic matricellular signaling molecules that regulate cell migration and proliferation (Zamilpa and Lindsey, 2010). In the goldfish, collagen accumulation is associated with the presence of activated fibroblasts in the repairing tissue. The accumulated connective tissue is subsequently resorbed, but not to the level found in uninjured ventricles. Various degrees of residual collagen and connective tissue have been reported in different types of injuries in fish (Chablais et al., 2011; Gonzalez-Rosa et al., 2011; Schnabel et al., 2011; Lafontant et al., 2012). Removal of residual connective tissue and collagen may extend beyond the regeneration phase in fish, or may only be reduced to a level that minimally impinges on normal cardiac function. Still it appears that in these fish effective turnover of collagen during repair favors myocardial regeneration in contrast to the regeneration-restrictive fibrosis manifest in mammalian models (Borchardt and Braun, 2007). In the goldfish, vascularization of the wounded area parallels that observed in the danios (Kim et al., 2010; Lafontant et al., 2012). Neovascularization also recedes as the myocardial tissue is reconstituted. We speculate that the angiogenic response facilitates heart repair, but whether it is required for regeneration is unclear and warrants further study.

The cellular and molecular basis of cardiac regeneration is an active area of scientific pursuit. Hyperplastic growth has long been reported in adult fish (Clark and Rodnick, 1998). In each of the danio species studied thus far, regeneration is primarily, or at least partially supported by cardiac myocyte proliferation. The current lack of specific cardiacrestricted nuclei markers for goldfish cardiac myocyte makes it difficult to unambiguously identify these specific nuclei and evaluate their cell cycle index. The caveats and limitations in identifying cardiac myocyte nuclei in tissue have been amply discussed (van Amerongen and Engel, 2008; Soonpaa et al., 2013). Indeed, in $10 \mu \mathrm{m}$ cryosections, the possibility of erroneously attributing the cell cycle activity of neighboring myocardial fibroblasts, endothelial cells, smooth muscle cells, or inflammatory cells to cardiac myocytes remains an important issue. However, the presence of partially differentiated cardiac myocytes in the repairing wound at 14 days in areas previously devoid of cells, and the replenishment of cardiac myocytes in the injured area strongly support the notion that cardiac myocyte proliferation contributes to the reconstitution of the ablated myocardial tissue in the goldfish. It is also possible that cardiac regeneration may involve additional mechanisms. Indeed a role for progenitor cells has been reported (Lepilina et al., 2006) and recently a role for atrial cardiac myocytes has been demonstrated (Zhang et al., 2013). Whether these mechanisms are also involved in goldfish heart regeneration is unknown.

In conclusion, while the zebrafish remains the primary model to study the cellular and molecular underpinnings of heart regeneration, comparative studies with other fish can provide valuable insight into the conserved mechanisms of heart regeneration in vertebrates. The rapid advances in whole genome sequencing and genetic manipulations in other fish including the goldfish (Du et al., 1992; Wang et al., 1995), may facilitate more mechanistic comparative studies and could lead to better understanding of the evolutionary processes that determine the extent, maintenance or loss of capacity for regeneration. While our study used goldfish with closely related standard lengths and body sizes, the age of the fish were undetermined. For comparative studies across fish species that lead to a broad understanding of regenerative capacities, future studies must consider controlling parameters such as age, developmental stage of the fish, as well as the method, location, 
and extent of the injury. A recent report describing the in vitro fertilization and developmental staging in goldfish will facilitate such studies (Tsai et al., 2013). Findings thus far suggest cardiac regeneration supported by adult cardiac myocyte hyperplastic growth may be conserved in fish. Regeneration in the goldfish myocardium, similar to the giant danio and zebrafish (Jopling et al., 2010; Kikuchi et al., 2010), appears to be supported at least in part by dedifferentiated or partially differentiated cardiac myocytes. Thus understanding the mechanisms of adult cardiac myocyte dedifferentiation and its relationship to robust cardiac myocyte cell cycle re-entry and progression is a potentially fruitful avenue for promoting cardiac regeneration in mammals.

\section{Acknowledgments}

We thank Margaret Gondo for her dedicated TEM help, Wendy Tomamichel for her technical help, and Clay Higginbotham and John Eskew for their animal care. We also thank Benjamin Golden and Adam May for their help in the sectioning and tissue staining. Jayne Williams for her administrative help and Barry Stein of The Electron Microscopy Center at Indiana University-Bloomington for his SEM help. JG, MH, AJ, TM, JR, TLD, and PJL are supported by Fisher Fund, and FDC and SRF at DePauw University. EB and ARB are supported by NIH/NEI grants EY017120 and P30EY007551.

\section{References}

Agnisola, C., Tota, B., 1994. Structure and function of the fish cardiac ventricle: flexibility and limitations. Cardioscience 5, 145-153.

Bader, D., Oberpriller, J., 1979. Autoradiographic and electron microscopic studies of minced cardiac muscle regeneration in the adult newt, Notophthalmus viridescens. J. Exp. Zool. 208, 177-193.

Bely, A.E., Nyberg, K.G., 2010. Evolution of animal regeneration: re-emergence of a field. Trends Ecol. Evol. 25, 161-170.

Bergmann, O., Bhardwaj, R.D., Bernard, S., Zdunek, S., Barnabe-Heider, F., Walsh, S. Zupicich, J., Alkass, K., Buchholz, B.A., Druid, H., Jovinge, S., Frisen, J., 2009. Evidence for cardiomyocyte renewal in humans. Science 324, 98-102.

Bernstein, J.J., 1964. Relation of spinal cord regeneration to age in adult goldfish. Exp. Neurol. 9, 161-174

Birnie, J.H., 1947. Regeneration and transplantation of fin rays in the goldfish. Anat. Rec 99,648

Borchardt, T., Braun, T., 2007. Cardiovascular regeneration in non-mammalian model systems: what are the differences between newts and man? Thromb. Haemost. 98 311-318.

Brockes, J.P., Kumar, A., Velloso, C.P., 2001. Regeneration as an evolutionary variable. J. Anat. 199, 3-11.

Busselen, P., 1982. Effect of potassium depolarization on sodium-dependent calcium efflux from goldfish heart ventricles and guinea-pig atria. J. Physiol. 327, 309-324.

Caskey, J.M., O'Brien, J.P., 1948. The cellular basis of regeneration of the caudal fin of the goldfish. Anat. Rec. 101, 710

Chablais, F., Veit, J., Rainer, G., Jazwinska, A., 2011. The zebrafish heart regenerates after cryoinjury-induced myocardial infarction. BMC Dev. Biol. 11, 21.

Cimini, V., Maresca, A., Tajana, G., Tota, B., 1977. On the heterogeneity of the fish heart ventricle: I. Preliminary morphological observations. Boll. Soc. Ital. Biol. Sper. 53 543-548.

Clark, R.J., Rodnick, K.J., 1998. Morphometric and biochemical characteristics of ventricular hypertrophy in male rainbow trout (Oncorhynchus mykiss). J. Exp. Biol. 201 1541-1552.

Divya, L., Beyo, R.S., Sreejith, P., Akbarsha, M.A., Oommen, O.V., 2010. Skeletal musclemelanocyte association during tadpole tail resorption in a tropical frog, Clinotarsus curtipes Jerdon (Anura, Ranoidea). Zoology 113, 175-183.

Du, S.J., Gong, Z.Y., Fletcher, G.L., Shears, M.A., King, M.J., Idler, D.R., Hew, C.L. 1992 Growth enhancement in transgenic Atlantic salmon by the use of an "all fish" chimeric growth hormone gene construct. Biotechnology 10, 176-181.

Ellison, G.M., Vicinanza, C., Smith, A.J., Aquila, I., Leone, A., Waring, C.D., Henning, B.J. Stirparo, G.G., Papait, R., Scarfo, M., Agosti, V., Viglietto, G., Condorelli, G., Indolfi, C., Ottolenghi, S., Torella, D., Nadal-Ginard, B., 2013. Adult c-kit(pos) cardiac stem cells are necessary and sufficient for functional cardiac regeneration and repair. Cell 154 $827-842$

Flink, I.L., 2002. Cell cycle reentry of ventricular and atrial cardiomyocytes and cells within the epicardium following amputation of the ventricular apex in the axolotl, Amblystoma mexicanum: Confocal microscopic immunofluorescent image analysis of bromodeoxyuridine-labeled nuclei. Anat. Embryol. 205, 235-244 (Berl).

Ganim, R.B., Peckol, E.L., Larkin, J., Ruchhoeft, M.L., Cameron, J.S., 1998. ATP-sensitive $\mathrm{K}+$ channels in cardiac muscle from cold-acclimated goldfish: characterization and altered response to ATP. Comp. Biochem. Physiol. A Mol. Integr. Physiol. $119,395-401$.
Garofalo, F., Imbrogno, S., Tota, B., Amelio, D., 2012. Morpho-functional characterization of the goldfish (Carassius auratus L.) heart. Comp. Biochem. Physiol. A Mol. Integr. Physiol. 163, 215-222.

Ge, W., Gallin, W.J., Strobeck, C., Peter, R.E., 1993. Cloning and sequencing of goldfish activin subunit genes: strong structural conservation during vertebrate evolution. Biochem. Biophys. Res. Commun. 193, 711-717.

Gonzalez-Rosa, J.M., Martin, V., Peralta, M., Torres, M., Mercader, N., 2011. Extensive scar formation and regression during heart regeneration after cryoinjury in zebrafish. Development 138, 1663-1674.

Greco, G., Tota, B., 1981. The ventricular myocardium of fish: aspects of comparative morphology physiology and pharmacology. II) Coronary circulation. Boll. Soc. Ital. Biol. Sper. 57, 2060-2066.

Herraez, M.P., Zapata, A.G., 1986. Structure and function of the melano-macrophage centres of the goldfish Carassius auratus. Vet. Immunol. Immunopathol. 12, 117-126.

Herraez, M.P., Zapata, A.G., 1991. Structural characterization of the melano-macrophage centres (MMC) of goldfish Carassius auratus. Eur. J. Morphol. 29, 89-102.

Hodgkinson, J.W., Ge, J.Q., Grayfer, L., Stafford, J., Belosevic, M., 2012. Analysis of the immune response in infections of the goldfish (Carassius auratus L.) with Mycobacterium marinum. Dev. Comp. Immunol. 38, 456-465.

Hu, N., Sedmera, D., Yost, H.J., Clark, E.B., 2000. Structure and function of the developing zebrafish heart. Anat. Rec. 260, 148-157.

Huang, W.C., Yang, C.C., Chen, I.H., Liu, Y.M., Chang, S.J., Chuang, Y.J., 2013. Treatment of glucocorticoids inhibited early immune responses and impaired cardiac repair in adult zebrafish. PLoS One 8, e66613.

Huntingford, F.A., 2012. The physiology of fish behaviour: a selective review of developments over the past 40 years (section sign). J. Fish Biol. 81, 2103-2126.

Jopling, C., Sleep, E., Raya, M., Marti, M., Raya, A., Belmonte, J.C., 2010. Zebrafish heart regeneration occurs by cardiomyocyte dedifferentiation and proliferation. Nature 464, 606-609.

Kajstura, J., Urbanek, K., Perl, S., Hosoda, T., Zheng, H., Ogorek, B., Ferreira-Martins, J., Goichberg, P., Rondon-Clavo, C., Sanada, F., D'Amario, D., Rota, M., Del Monte, F., Orlic, D., Tisdale, J., Leri, A., 2010. Anversa. P. Cardiomyogenesis in the adult human heart. Circ. Res. 107, 305-315.

Kikuchi, K., Poss, K.D., 2012. Cardiac regenerative capacity and mechanisms. Annu. Rev. Cell Dev. Biol. 28, 719-741

Kikuchi, K., Holdway, J.E., Werdich, A.A., Anderson, R.M., Fang, Y., Egnaczyk, G.F., Evans, T., Macrae, C.A., Stainier, D.Y., Poss, K.D., 2010. Primary contribution to zebrafish heart regeneration by gata4(+) cardiomyocytes. Nature 464, 601-605.

Kim, J., Wu, Q., Zhang, Y., Wiens, K.M., Huang, Y., Rubin, N., Shimada, H., Handin, R.I., Chao, M.Y., Tuan, T.L., Starnes, V.A., Lien, C.L., 2010. PDGF signaling is required for epicardial function and blood vessel formation in regenerating zebrafish hearts. Proc. Natl. Acad. Sci. U. S. A. 107, 17206-17210.

Laflamme, M.A., Murry, C.E., 2011. Heart regeneration. Nature 473, 326-335.

Lafontant, P.J., Burns, A.R., Grivas, J.A., Lesch, M.A., Lala, T.D., Reuter, S.P., Field, L.J., Frounfelter, T.D., 2012. The giant danio (D. aequipinnatus) as a model of cardiac remodeling and regeneration. Anat. Rec. 295, 234-248 (Hoboken)

Leferovich, J.M., Bedelbaeva, K., Samulewicz, S., Zhang, X.M., Zwas, D., Lankford, E.B. Heber-Katz, E., 2001. Heart regeneration in adult MRL mice. Proc. Natl. Acad. Sci. U. S. A. $98,9830-9835$.

Lepilina, A., Coon, A.N., Kikuchi, K., Holdway, J.E., Roberts, R.W., Burns, C.G., Poss, K.D. 2006. A dynamic epicardial injury response supports progenitor cell activity during zebrafish heart regeneration. Cell 127, 607-619.

Lien, C.L., Schebesta, M., Makino, S., Weber, G.J., Keating, M.T., 2006. Gene expression analysis of zebrafish heart regeneration. PLoS Biol. 4, e260.

Matsukawa, T., Arai, K., Koriyama, Y., Liu, Z., Kato, S., 2004. Axonal regeneration of fish optic nerve after injury. Biol. Pharm. Bull. 27, 445-451.

Meyer, A., Biermann, C.H., Orti, G., 1993. The phylogenetic position of the zebrafish (Danio rerio), a model system in developmental biology: an invitation to the comparative method. Proc. Biol. Sci. 252, 231-236.

Mollova, M., Bersell, K., Walsh, S., Savla, J., Das, L.T., Park, S.Y., Silberstein, L.E., Dos Remedios, C.G., Graham, D. Colan, S., Kuhn, B., 2013. Cardiomyocyte proliferation contributes to heart growth in young humans. Proc. Natl. Acad. Sci. U. S. A. 110, 1446-1451.

Parente, V., Balasso, S., Pompilio, G., Verduci, L., Colombo, G.I., Milano, G., Guerrini, U., Squadroni, L., Cotelli, F., Pozzoli, O., Capogrossi, M.C., 2013. Hypoxia/reoxygenation cardiac injury and regeneration in zebrafish adult heart. PLoS One 8, e53748.

Piatkowski, T., Muhlfeld, C., Borchardt, T., Braun, T., 2013. Reconstitution of the myocardium in regenerating newt hearts is preceded by transient deposition of extracellular matrix components. Stem Cells Dev. 22, 1921-1931.

Porrello, E.R., Mahmoud, A.I., Simpson, E., Hill, J.A., Richardson, J.A., Olson, E.N., Sadek, H.A., 2011. Transient regenerative potential of the neonatal mouse heart. Science 331, $1078-1080$

Porrello, E.R., Mahmoud, A.I., Simpson, E., Johnson, B.A., Grinsfelder, D., Canseco, D., Mammen, P.P., Rothermel, B.A., Olson, E.N., Sadek, H.A., 2013. Regulation of neonatal and adult mammalian heart regeneration by the miR-15 family. Proc. Natl. Acad. Sci. U. S. A. 110, 187-192.

Poss, K.D., Wilson, L.G., Keating, M.T., 2002. Heart regeneration in zebrafish. Science 298, $2188-2190$

Raya, A., Koth, C.M., Buscher, D., Kawakami, Y., Itoh, T., Raya, R.M., Sternik, G., Tsai, H.J., Rodriguez-Esteban, C., Izpisua-Belmonte, J.C., 2003. Activation of Notch signaling pathway precedes heart regeneration in zebrafish. Proc. Natl. Acad. Sci. U. S. A. 100 (Suppl. 1), 11889-11895.

Santer, R.M., 1985. Morphology and innervation of the fish heart. Adv. Anat. Embryol. Cell Biol. 89, 1-102.

Schnabel, K., Wu, C.C., Kurth, T., Weidinger, G., 2011. Regeneration of cryoinjury induced necrotic heart lesions in zebrafish is associated with epicardial activation and cardiomyocyte proliferation. PLoS One 6, e18503. 
Senyo, S.E., Steinhauser, M.L., Pizzimenti, C.L., Yang, V.K., Cai, L., Wang, M., Wu, T.D., Guerquin-Kern, J.L., Lechene, C.P., Lee, R.T., 2013. Mammalian heart renewal by pre-existing cardiomyocytes. Nature 493, 433-436.

Smith, M.E., Coffin, A.B., Miller, D.L., Popper, A.N., 2006. Anatomical and functional recovery of the goldfish (Carassius auratus) ear following noise exposure. J. Exp. Biol. 209, 4193-4202.

Soonpaa, M.H., Field, L.J., 1997. Assessment of cardiomyocyte DNA synthesis in normal and injured adult mouse hearts. Am. J. Physiol. 272, H220-H226.

Soonpaa, M.H., Rubart, M., Field, L.J., 2013. Challenges measuring cardiomyocyte renewal. Biochim. Biophys. Acta 1833, 799-803.

Thamamongood, T.A., Furuya, R., Fukuba, S., Nakamura, M., Suzuki, N., Hattori, A., 2012. Expression of osteoblastic and osteoclastic genes during spontaneous regeneration and autotransplantation of goldfish scale: a new tool to study intramembranous bone regeneration. Bone 50, 1240-1249.

Tsai, H.Y., Chang, M., Liu, S.C., Abe, G., Ota, K.G., 2013. Embryonic development of goldfish (Carassius auratus): a model for the study of evolutionary change in developmental mechanisms by artificial selection. Dev. Dyn. 242, 1262-1283.

van Amerongen, M.J., Engel, F.B., 2008. Features of cardiomyocyte proliferation and its potential for cardiac regeneration. J. Cell. Mol. Med. 12, 2233-2244.

van Amerongen, M.J., Harmsen, M.C., Petersen, A.H., Popa, E.R., van Luyn, M.J., 2008. Cryoinjury: a model of myocardial regeneration. Cardiovasc. Pathol. 17, 23-31.
Vargas-Gonzalez, A., Prado-Zayago, E., Leon-Olea, M., Guarner-Lans, V., Cano-Martinez, A., 2005. Myocardial regeneration in Ambystoma mexicanum after surgical injury. Arch. Cardiol. Mex. 75 (Suppl. 3), 21-29 (S3).

Vidal, G., Scheffler, B., Michel, A., D'Surney, S.J., 2004. Genomic and phylogenic comparisons of the alpha-globin and beta-globin intergenic sequences between zebra fish (Danio rerio) and six closely related Cyprinindae species. DNA Cell Biol. 23, 325-334.

Walsh, S., Ponten, A., Fleischmann, B.K., Jovinge, S., 2010. Cardiomyocyte cell cycle control and growth estimation in vivo-an analysis based on cardiomyocyte nuclei. Cardiovasc. Res. 86, 365-373.

Wang, R., Zhang, P., Gong, Z., Hew, C.L., 1995. Expression of the antifreeze protein gene in transgenic goldfish (Carassius auratus) and its implication in cold adaptation. Mol. Mar. Biol. Biotechnol. 4, 20-26.

Witman, N., Murtuza, B., Davis, B., Arner, A., Morrison, J.I., 2011. Recapitulation of developmental cardiogenesis governs the morphological and functional regeneration of adult newt hearts following injury. Dev. Biol. 354, 67-76.

Zamilpa, R., Lindsey, M.L., 2010. Extracellular matrix turnover and signaling during cardiac remodeling following MI: causes and consequences. J. Mol. Cell. Cardiol. 48, 558-563.

Zhang, R., Han, P., Yang, H., Ouyang, K., Lee, D., Lin, Y.F., Ocorr, K., Kang, G., Chen, J. Stainier, D.Y., Yelon, D., Chi, N.C., 2013. In vivo cardiac reprogramming contributes to zebrafish heart regeneration. Nature 498, 497-501.

Zuasti, A., Jara, J.R., Ferrer, C., Solano, F., 1989. Occurrence of melanin granules and melanosynthesis in the kidney of Sparus auratus. Pigment Cell Res. 2, 93-99. 